\title{
O PROCESSO DE ORGANIZAÇÃO INTRATÓPICA EM EDITORIAIS DO JORNAL O ESTADO DE S. PAULO PUBLICADOS NA PRIMEIRA METADE DO SÉCULO XX
}

\author{
THE PROCESS OF INTRATOPIC ORGANIZATION OF \\ EDITORIALS PUBLISHED IN THE NEWSPAPER $O$ \\ ESTADO DE S. PAULO IN THE FIRST HALF OF THE \\ $20^{\mathrm{TH}}$ CENTURY
}

Eduardo Penhavel"

Resumo: A organização tópica éa organização de um texto em tópicos hierarquicamente inter-relacionados e a construção e linearização de grupos de enunciados que desenvolvem esses tópicos. Chama-se de segmento tópico mínimo cada grupo de enunciados que desenvolve um dos tópicos mais específicos da hierarquização tópica do texto, e a combinação de enunciados dentro desses segmentos mínimos constitui a denominada organização intratópica. Inserido no âmbito teórico-metodológico da Gramática Textual-Interativa, este trabalho tem o objetivo de analisar a organização intratópica de editoriais da primeira metade do século XX do jornal O Estado de S. Paulo. Os resultados apresentados indicam que tais editoriais seguem uma regra geral de organização intratópica, fundada na combinação entre as unidades de posição e suporte, as quais se caracterizam por uma oposição entre maior e menor grau de abrangência temática, respectivamente.

Palavras-chave: Organização tópica; Tópico discursivo; Processos de construção textual.

Abstract: Topic organization is the organization of a text into hierarchically interrelated topics and the construction and sequencing of groups of utterances that develop these topics. Each group of utterances that develops one of the most specific topics is called minimal topic segment. The combination of utterances inside minimal topic segments is the so-called intratopic organization. Within Textual-Interactive Grammar, this paper aims at analyzing the intratopic organization of editorials published in the newspaper O Estado de S. Paulo, in the first half of the $20^{\text {th }}$ century. The

"Doutor em Linguística pela Universidade Estadual de Campinas (UNICAMP). Docente da Universidade Estadual Paulista (UNESP), campus de São José do Rio Preto, SP, Brasil. E-mail: eduardo.penhavel@unesp.br. 
results indicate that these editorials follow a general rule of intratopic organization based on the combination between two types of units, named position and support, which are characterized by an opposition between general and specific thematic approach, respectively.

Keywords: Topic organization; Discourse topic; Processes of text construction.

\section{CoNSIDERAÇõES INICIAIS}

Este artigo insere-se no âmbito da Linguística Textual (cf. $\mathrm{KOCH}, 2004$ ), área dos estudos linguísticos que assume o texto como objeto de estudo. Mais especificamente, o trabalho filia-se à Gramática Textual-Interativa (doravante GTI - cf. JUBRAN; KOCH, 2006; JUBRAN, 2007), quadro teórico-metodológico especializado no estudo dos chamados processos de construção textual (ou processos constitutivos do texto). Os principais processos reconhecidos e investigados pela GTI são a organização tópica, a referenciação, a repetição, o parafraseamento, a parentetização, a correção e a tematização-rematização. Completa a agenda de estudos da GTI a análise dos denominados marcadores discursivos, entendidos como expressões linguísticas que assessoram o funcionamento dos processos de construção de textos.

Abordamos aqui a organização tópica, processo central de construção do texto na ótica da GTI. Trata-se da organização do texto em partes e subpartes, em termos de estruturação temática, o que compreende três processos efetivados simultaneamente: a configuração do texto segundo uma rede de tópicos (temas) hierarquicamente inter-relacionados, a construção de grupos de enunciados que desenvolvem esses tópicos e a organização linear desses grupos de enunciados.

Os grupos de enunciados que desenvolvem os tópicos de um texto são chamados de segmentos tópicos (SegTs), sendo tratados como SegTs mínimos os grupos que desenvolvem os tópicos mais específicos da hierarquização tópica. São distinguidos dois níveis de organização tópica: (i) a organização intertópica, que compreende o relacionamento entre tópicos e entre seus respectivos SegTs - inclusive entre SegTs mínimos; (ii) a organização intratópica, que é a combinação de (grupos de) enunciados dentro de SegTs mínimos.

Neste artigo, tratamos desse segundo nível da organização tópica. Nosso objetivo é descrever o processo de organização intratópica de editoriais do jornal O Estado de S. Paulo publicados na primeira metade do século XX.

O exemplo em (1) ilustra um dos SegTs mínimos que analisamos, a fim de propiciar uma visualização inicial dessa unidade de análise (bem como uma breve amostra dos editoriais em pauta):

(1) Assume proporções verdadeiramente alarmantes a quantidade de pernilongos que actualmente infestam a nossa capital. Não ha memoria de uma invasão assim consideravel 
e assustadora desses insectos, tão perigosos vehiculos e propagadores de enfermidades graves. S. Paulo jamais se conheceu completamente livre desses incommodos hospedes, é bem verdade: mas nunca se registou a sua presença em quantidades tão prodigiosas como agora acontece. Não haverá um habitante desta capital que tenha já ouvido falar, mesmo de quando havia pantanos e brejos dentro do perimetro urbano, de uma invasão igual á desses sanguisedentos mosquitos que actualmente dominam a cidade. Quer de dia, quer de noite, nos cafés, nas lojas, nos theatros, nos escriptorios, nas ruas, nas praças, nos hoteis, nas residencias, onde quer que alguem se ponha mais ou menos immovel por um minuto ou dois, la o vao assaltar um exercito dos trombeteantes culicideos, que o ferrotoam, que lhe sugam o sangue, que lhe innoculam germens de toda casta, deixando-lhe na pelle a marca inconfundivel das suas façanhas (O Estado de S. Paulo, 27/04/1923).

O editorial em que ocorre esse SegT mínimo trata de uma invasão de pernilongos que estaria ocorrendo na cidade de São Paulo, na época da publicação do texto. Como explicaremos adiante, esse SegT, o primeiro do editorial, desenvolve o tópico Proporções alarmantes da invasão de pernilongos na cidade de São Paulo (na sequência, o editorial contém mais três SegTs mínimos, que tratam, respectivamente, dos tópicos A possibilidade de consequências graves da invasão de pernilongos, A ausência de providências quanto à invasão de pernilongos e A necessidade de medidas quanto às inundações dos rios da cidade, como forma de prevenção).

$\mathrm{O}$ artigo ora apresentado vincula-se simultaneamente a duas frentes de investigação: (i) a teorização acerca do processo de organização intratópica; (ii) o estudo histórico do português brasileiro.

A primeira delas assenta-se em nossa constatação, demonstrada em Penhavel (2010), da existência de expressiva regularidade no processo de organização intratópica em um conjunto de relatos de opinião, sistematicidade que apuramos pela identificação, nesse material, de uma regra geral de organização intratópica. A partir dessa constatação, e considerando que os relatos analisados - extraídos do Banco de Dados IBORUNA (cf. GONÇALVES, 2005) - seriam uma amostra de fala correspondente a um gênero textual, formulamos, na ocasião, a hipótese de que a organização intratópica, nos diversos gêneros textuais, seria também um processo sistemático, passível de descrição em termos de regras gerais. De acordo com essa hipótese, cada gênero seguiria uma determinada regra. ${ }^{1}$ Com base nessa perspectiva, propusemos um programa de pesquisa voltado para a análise da organização intratópica em diferentes gêneros textuais, com o objetivo de investigar tal hipótese e, no caso de sua confirmação, identificar um inventário, o mais completo possível, das regras de organização intratópica com as quais os falantes lidam na construção e na interpretação de textos.

\footnotetext{
${ }^{1}$ A nosso ver, essa hipótese não pressupõe necessariamente que a regra geral seguida por um gênero seja diferente das regras de todos os outros gêneros. Diferentes gêneros poderiam compartilhar uma mesma regra. Não se trata de considerar que cada gênero teria uma regra geral própria, mas de considerar que, em cada gênero, a organização intratópica seria estruturada conforme uma regra (independentemente de essa regra também ser usada em outros gêneros).
} 
O presente artigo situa-se nesse contexto de investigação. Ao tratar de editoriais paulistas novecentistas, o trabalho incide sobre um material ainda não analisado no âmbito do referido programa, indica a existência de uma regra geral nesse material e a descreve detalhadamente. Desse modo, esperamos contribuir para a corroboração da hipótese da sistematicidade da organização intratópica e para o empreendimento da descrição de diferentes regras gerais que norteiam esse processo. ${ }^{2}$

Paralelamente, este trabalho integra um projeto de pesquisa interinstitucional, desenvolvido no Brasil, conhecido como Projeto para a História do Português Brasileiro (PHPB - cf. CASTILHO, 1998). Esse projeto compreende a análise da diacronia de diversos fenômenos do português, conforme seu desenvolvimento em diferentes regiões do país, abarcando, assim, dentre outros, o Projeto de História do Português Paulista (PHPP - cf. ALMEIDA, 2017). Tanto no âmbito do $\mathrm{PHPB}$, quanto do PHPP, um conjunto de pesquisas dedica-se à diacronia de processos de construção textual. Tais pesquisas examinam a diacronia de um dado processo sempre como parte da evolução histórica de determinado gênero textual e incluem, dentre outros, o estudo da diacronia da organização tópica na esfera da história de editoriais.

Nosso trabalho faz parte desse último estudo, incorporando-se mais diretamente ao PHPP. Focalizamos aqui o funcionamento de um dos níveis da organização tópica, em editoriais paulistas publicados em um dos recortes sincrônicos previstos pelo PHPP (e igualmente pelo $\mathrm{PHPB}$ - a primeira metade do século XX. O propósito aqui, a esse respeito, é oferecer resultados que possam ser comparados aos de análises voltadas a outras sincronias, contribuindo para a descrição da diacronia da organização tópica em editoriais, para o traçado da história do português paulista e, em última instância, do português brasileiro.

Feitas estas considerações iniciais, sintetizamos, na seção abaixo, os fundamentos teórico-metodológicos do trabalho, apresentamos, em seguida, nossa análise de dados e, então, elaboramos as considerações finais.

\section{Fundamentos TEÓRICO-METODOLÓgICOS}

A GTI filia-se a um paradigma teórico que assume que as línguas humanas naturais constituem uma forma de interação social, pela qual os sujeitos realizam tarefas comunicativas de troca de representações, executam metas, manipulam interesses, no contexto de um espaço discursivo sempre orientado para os parceiros da comunicação, isto é, num contexto em que os interlocutores se situam reciprocamente, em função de suas visões mútuas sobre papéis

\footnotetext{
${ }^{2}$ Dentre outros trabalhos que descrevem a organização intratópica em diferentes materiais e também apontam para a confirmação da hipótese em questão, podem ser citadas as pesquisas de Oliveira (2016), Garcia (2018) e Hanisch (2019), que analisam SegTs mínimos, respectivamente, de cartas de leitor, editoriais e artigos de opinião - nos três casos, são analisados dados do início do século XXI.
} 
sociais, conhecimentos de mundo, atitudes, propósitos e reações assumidas no intercâmbio linguístico (JUBRAN, 2006a, 2007).

Alinhada a essa visão de língua, a GTI concebe que o texto, seu objeto de estudo, caracteriza-se, dentre outras propriedades, como uma combinação de enunciados interacionalmente significativa, um complexo de enunciados cujo processamento (construção e interpretação) constitui uma "atividade sócio-comunicativa, que mobiliza um conjunto de conhecimentos não só de ordem lingüístico-textual, como também interacional, a respeito do jogo de atuação comunicativa que se realiza pela linguagem" (JUBRAN, 2007, p. 313). Em outros termos, a GTI entende que o texto compreende a construção e a organização de conteúdo informacional (representacional) num nível superior ao do enunciado e que esse processo é constitutivamente integrado à dimensão interacional da linguagem. ${ }^{3}$

Mais especificamente, em consonância com as noções de língua e de texto que assume, a GTI estabelece uma série de princípios teórico-metodológicos para o estudo do texto, em particular para o estudo de processos de construção textual. Um primeiro princípio é o de que os processos textuais têm suas propriedades e funções definidas no uso, nas situações concretas de interlocução, coenvolvendo as circunstâncias enunciativas. Entende-se que a forma específica e completa pela qual um processo textual se atualiza em um texto depende do contexto particular em que o processo e o texto ocorrem.

Na mesma direção desse primeiro princípio, os trabalhos na GTI vêm assumindo (e atestando empiricamente) que os processos de construção de textos estão associados aos gêneros textuais, já que os gêneros congregam as ações particulares realizadas por meio de textos (dentre as quais, as finalidades sociocomunicativas dos textos), e os processos textuais se configurariam em função das ações realizadas pelos textos em que ocorrem. Assume-se que a implementação de um processo pode exibir padrões diferentes em gêneros diferentes, assim como em diferentes períodos históricos de um mesmo gênero. Desse modo, prevê-se que cada estudo de um dado processo, tanto em perspectiva sincrônica, quanto diacrônica, seja sempre situado no contexto de algum gênero textual - o que significa, no caso da segunda perspectiva, identificar a diacronia de um dado processo no interior da evolução histórica de um dado gênero (cf. JUBRAN, 2010; PENHAVEL, 2017) ${ }^{4}$

Outro princípio central da GTI é a compreensão de que os fatores interacionais envolvidos no intercâmbio verbal são constitutivos do texto e inerentes à expressão linguística. Considera-se que as condições enunciativas que sustentam a ação verbal mostram-se no próprio texto, por meio de escolhas comunicativamente adequadas à situação interativa.

${ }^{3}$ A dimensão da construção/organização de conteúdo informacional num nível superior ao do enunciado pode ser aproximada ao que seria uma integração entre as macrofunções ideacional e textual da linguagem postuladas por Halliday (1978), e a dimensão interacional aproxima-se da macrofunção interpessoal concebida pelo autor.

${ }^{4}$ Aqui, bem como na GTI de modo geral, sob uma perspectiva que, em última instância, remonta a Bakhtin (1992), os gêneros textuais são entendidos como espécies de texto relativamente estáveis, caracterizadas em termos de estrutura composicional, conteúdo, estilo e, sobretudo, finalidade sociocomunicativa (cf. KOCH, 2003; MARCUSCHI, 2008). 
Entende-se que, enquanto realização efetiva da atividade interacional, o texto emerge de um jogo de atuação comunicativa, que se projeta em sua superfície (JUBRAN, 2007).

Esse princípio é fundamental na GTI, ao contribuir para sustentar a admissão da existência de sistematicidade no processo de construção de textos. De acordo com tal princípio, como explica Jubran (2007), a atividade enunciativa deixa, na própria superfície textual, marcas do processamento do texto pelos interlocutores, tornando possível ao analista, pela observação dessas marcas, a depreensão de regularidades no processo de construção textual. A seguinte postulação da autora exibe o reconhecimento da sistematicidade da construção textual e aponta alguns de seus fatores:

A GTI deve [...] apontar regularidades relacionadas ao processamento dos procedimentos de elaboração do texto, aferindo o caráter sistemático deles pela sua recorrência em contextos definidos, pelas marcas formais que os caracterizam e pelo preenchimento de funções textual-interativas proeminentes que os especificam (JUBRAN, 2007, p. 316). ${ }^{5}$

Nesse sentido, nosso método para identificação de unidades constituintes de SegTs mínimos considera, dentre outros fatores, (i) a recorrência de tipos iguais de (sub)unidades em partes correspondentes de diferentes SegTs, (ii) a presença de marcas formais (como o uso de marcadores discursivos) nas transições entre possíveis (sub)unidades, (iii) as funções que essas possíveis (sub)unidades desempenham no desenvolvimento do SegT e (iv) a possibilidade de diferenciação entre (sub)unidades associada a diferenças nos próprios conteúdos informacionais expressos em cada uma, em termos, por exemplo, de formas distintas de referenciação tópica.

Ainda ao tratar da depreensão de regularidades na construção textual, Jubran (2007, p. 316) ressalta a necessidade de se contabilizar, na análise linguística, fatores responsáveis não só pelo "caráter determinístico (restrições)", mas também pelo caráter "probabilístico (escolhas facultadas ao falante)" das expressões produzidas na fala. Em nosso entendimento de regras gerais de organização intratópica, pressupomos esse caráter probabilístico dos traços dos processos textuais, concebendo-as como princípios que se manifestam não necessariamente em todas as instâncias de organização intratópica, mas que se aplicam normalmente na maioria delas.

Com base nesses princípios (dentre outros, não diretamente relevantes para o presente artigo), a GTI assume o texto como objeto de estudo, dedicando-se à análise de processos de construção textual, dentre os quais a organização tópica.

\footnotetext{
${ }^{5}$ Segundo nosso ponto de vista, a sistematicidade na construção textual manifesta-se por indícios da enunciação projetados na superfície textual, conforme postula Jubran (2007), assim como por regularidades, a cada gênero, nas relações entre os próprios conteúdos informacionais expressos em um texto (conforme poderá ser visto em nossa análise de dados).
} 
Na GTI, nos estudos sobre organização tópica, o conceito de tópico (ou tópico discursivo) não remete a noções como tópico-comentário ou tema-rema, relativas à estrutura da sentença (tratadas, por exemplo, em Ilari (1992)). O conceito de tópico (assim como o conceito quase sinônimo de tema) assenta-se na ideia de que, em um texto, além de cada ato de referência individual realizado por cada expressão referencial materialmente presente nos enunciados, todos os enunciados, de alguma forma, remetem a (tratam de) um mesmo referente geral, reconhecível por uma abstração interpretativa dos interlocutores (e do analista). Esse referente comum e geral constitui o que se considera como o tópico/tema do texto. Similarmente, os enunciados do texto podem dividir-se em grupos, de modo que os enunciados de cada grupo compartilhem também um referente geral - o tópico/tema desse grupo. Ou seja, na GTI, um tópico/tema pode ser entendido como um referente geral, comum a um grupo de enunciados - trata-se, pois, de uma noção próxima do conceito de tópico discursivo (discourse topic) tratado em Brown e Yule (1983), no quadro da Análise do Discurso Americana, e do conceito de tópico de discurso (topic of discourse) de van Dijk (1982), formulado na própria Linguística de Texto.6,

Partindo dessa noção de tópico/tema, o processo de organização tópica é concebido como a estruturação de um texto em partes e subpartes, em tópicos e subtópicos. Caracterizase por duas propriedades: organicidade e centração (cf. JUBRAN, 2006b; PINHEIRO, 2005). A primeira compreende a hierarquização e a linearização tópicas. A hierarquização diz respeito à construção do texto acerca de uma rede de tópicos hierarquicamente inter-relacionados. Tratase da organização do texto de modo que sejam instauradas "dependências de superordenação e subordenação entre tópicos que se implicam pelo grau de abrangência do assunto" (JUBRAN, 2006b, p. 94). A Figura 1 exibe a hierarquização tópica de um texto hipotético composto por um tópico global, que abrangeria três tópicos mais específicos, cada um dos quais constituído por dois tópicos ainda mais específicos:

\footnotetext{
${ }^{6}$ Aqui, na definição de tópico/tema, usamos o termo referente (e outros correlatos como fazer referência, remeter). Porém, não se trata de adotar uma visão meramente referencialista sobre a relação entre a linguagem e a realidade, pela qual as expressões linguísticas apenas representam entidades do mundo, pré-existentes ao texto. Na verdade, a esse respeito, seguimos a visão praticada nos estudos textuais de orientação sociocognitivista e interacionista (cf. KOCH, 2004), segundo a qual as entidades a que o texto se refere são construídas no próprio texto, sendo, pois, objetos de discurso (não objetos do mundo), e as expressões linguísticas não apenas remetem a esses objetos, mas contribuem para a construção de sua significação, realizando não simplesmente uma ação de fazer referência, mas de referenciação. Dessa forma, utilizamos o termo referente e seus correlatos por serem mais tradicionais e conhecidos nos estudos linguísticos, mas os empregamos nas acepções aqui esclarecidas. Nesse sentido, o tópico pode ser compreendido como o objeto de discurso mais geral de um texto (ou de um grupo de enunciados), para cuja construção todos os enunciados contribuem.

${ }^{7}$ Em nossos trabalhos, temos optado por considerar os termos tópico e tema, em certa medida, como sinônimos. Porém, reservamos ao primeiro um uso mais restrito, aplicando-o apenas ao nível da organização intertópica (abaixo explicada) - o que inclui sua aplicação ao referente central de cada SegT mínimo do texto. Já o termo tema é empregado de modo mais amplo, sendo aplicado tanto ao nível intertópico (quando é sinônimo de tópico), quanto ao intratópica. Ou seja, todo tópico pode ser também chamado de tema, mas nem tudo a que nos referimos pelo termo tema pode ser também referido por tópico. Na seção 2, ao tratarmos especificamente do nível intratópico, retomamos essa relação entre os termos tópico e tema.
} 
Figura 1: Representação da hierarquização tópica de um texto hipotético.

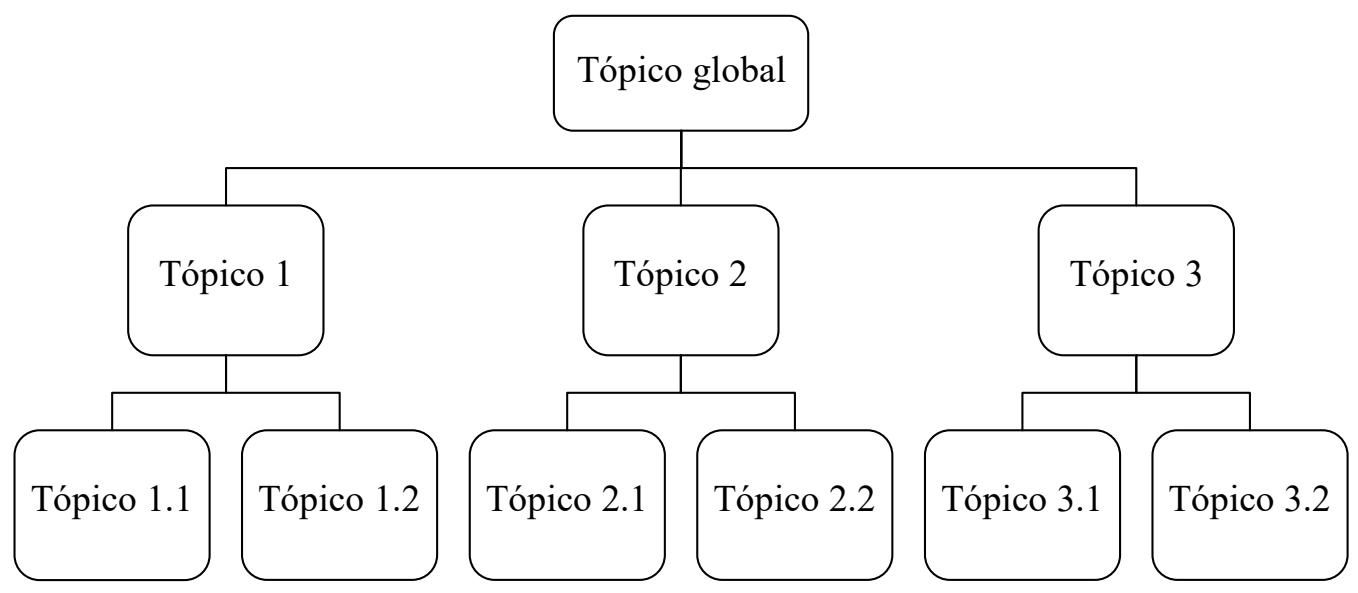

Fonte: elaboração própria.

A linearização refere-se à ordem de expressão dos tópicos do texto, bem como ao desenvolvimento dos tópicos em termos de continuidade e descontinuidade. O primeiro caso ocorre quando, na progressão textual, um novo tópico é iniciado após a finalização do anterior. O segundo caso se verifica quando há interrupções no desenvolvimento de um tópico, como a suspensão temporária de um tópico em curso para desenvolvimento completo de outro, depois do qual há a retomada e conclusão do tópico suspendido.

A centração refere-se à construção de grupos de enunciados que desenvolvem os tópicos do texto. Especificamente, é a propriedade que um texto apresenta de conter, para cada tópico, um conjunto de enunciados semanticamente concernentes entre si e que focalizam esse tópico num dado segmento textual. ${ }^{8}$ Engloba, assim, três traços que, com base em Jubran (2006b), podem ser assim entendidos: (i) concernência: relação de interdependência semântica entre um conjunto de enunciados - implicativa, associativa, exemplificativa, ou de outra ordem; (ii) relevância: convergência desses enunciados para a focalização de um tópico comum; (iii) pontualização: reunião desses enunciados num momento particular do texto.

Cada grupo de enunciados que desenvolve um tópico constitui uma instância da unidade chamada de SegT, e os menores SegTs de um texto constituem os SegTs mínimos - no exemplo da Figura 1, os SegTs mínimos seriam as porções textuais que desenvolveriam os tópicos 1.1, 1.2, 2.1, 2.2, 3.1 e 3.2. Conforme mencionado, são distinguidos dois níveis de organização tópica: (i) o intertópico, que é o relacionamento entre tópicos e entre SegTs, inclusive entre SegTs mínimos; (ii) o intratópico, isto é, o encadeamento de (grupos de) enunciados dentro de SegTs mínimos, nível de análise aqui em pauta.

\footnotetext{
${ }^{8}$ Como a organização tópica envolve hierarquização de tópicos, um grupo de enunciados que desenvolve um dado tópico é naturalmente o conjunto dos grupos que desenvolvem os eventuais subtópicos desse tópico. No exemplo da Figura 1,0 grupo de enunciados que desenvolve o tópico 1 é a junção do grupo que desenvolve 1.1 com o que desenvolve 1.2.
} 
As propriedades de centração e organicidade, conforme postuladas em Jubran (2006b) e acima apresentadas, caracterizam, a nosso ver, sobretudo a organização intertópica, aplicando-se aos diferentes gêneros textuais. Já a organização intratópica, como tem sido indicado em diversos trabalhos (cf. seção anterior), seria regida por regras que variariam de acordo com os gêneros.

Pelo que tem sido demonstrado nos referidos trabalhos, a organização intratópica realiza-se com base nos próprios traços da centração tópica, porém, num plano de funcionamento que envolve um grau de centração mais específico do que o que se verifica na organização intertópica. Assim, para a identificação de (sub)unidades intratópicas e suas regras de combinação, o método que utilizamos compreende justamente uma aplicação dos traços da centração de forma mais específica do que seu uso para distinção de SegTs e de SegTs mínimos no nível intertópico.

A esse respeito, com base no traço da concernência, nossa metodologia estabelece que se verifique se é possível reconhecer, na estruturação do SegT mínimo, alguma divisão entre (sub)grupos de enunciados na qual, em cada (sub)grupo, haja uma concernência entre enunciados mais específica do que a concernência geral que confere unidade ao SegT todo. Tal procedimento resulta numa divisão interna do SegT na qual cada (sub)grupo abordaria um elemento do tópico do SegT (ou uma fase de seu desenvolvimento).

Tendo em vista o traço da relevância, o método prevê que a averiguação de possíveis (sub)grupos de enunciados dentro do SegT leve em conta que eles possam distinguir-se entre si também em termos de seu grau de relevância em relação ao foco do desenvolvimento do tópico do SegT, o que revela (sub)grupos mais e menos relevantes (centrais e subsidiários), dado crucial para a identificação das funções desses (sub)grupos na construção do SegT.

Ainda o traço da pontualização fundamenta nossa metodologia. Esse traço prediz que cada tópico de um texto seja desenvolvido em uma porção do texto (um SegT). Isso significa que um texto não trata, a todo momento, de todos os seus tópicos, mas, a cada momento, focaliza um tópico, e, assim, um texto compreende um encadeamento de SegTs (que abarca o encadeamento de SegTs mínimos). No mesmo sentido, nosso método assume que também cada elemento do tópico de um SegT mínimo (ou cada estágio de seu desenvolvimento) possa ser focalizado em um ponto específico dentro do SegT (em um grupo de enunciados), podendo o SegT ser composto pelo encadeamento de grupos de enunciados.

Com base, então, nos pressupostos acima sintetizados, procedemos, na próxima seção, à análise de dados. 


\section{Análise de dados}

$\mathrm{Na}$ pesquisa aqui relatada, analisamos os editoriais da primeira metade do século $\mathrm{XX}$ coletados, no âmbito do PHPP, pela equipe responsável pelo estudo diacrônico de processos de construção textual. Relativamente a esse período, o grupo coletou 24 editoriais do jornal O Estado de S. Paulo, periódico tradicional do estado, publicados entre 1923 e 1928, anos mais centrais dessa metade do século. Nessa coleta de material, com base principalmente em Gomes (2007) e Zavan (2009), a equipe considerou o editorial como um gênero textual essencialmente argumentativo, que aborda normalmente temas de interesse coletivo de ordem social, política e/ou econômica, que veicula o posicionamento de um jornal ou revista e que é marcado pela ausência de assinatura de um autor particular - sendo essa também a concepção que assumimos acerca do gênero (cf. ALMEIDA, 2017). ${ }^{9}$

Em nossa pesquisa, partindo das propriedades tópicas de centração e organicidade, dividimos em SegTs mínimos cada um dos 24 editoriais selecionados, o que resultou no total de 90 SegTs mínimos. Analisando a estruturação interna desses SegTs, apuramos que 72,2\% deles (65/90 casos) seguem um mesmo mecanismo de estruturação. Considerando tratar-se de uma regularidade percentualmente expressiva, assumimos esse mecanismo como uma regra geral de organização intratópica no material analisado.

De acordo com essa regra, o SegT mínimo conterá um, ou dois, grupo(s) de enunciados concentrado(s) em expressar (sintetizar) o próprio tópico do SegT e um, ou mais de um, grupo de enunciados concentrado em desenvolver (discorrer sobre) o tópico mediante a focalização de uma temática formulada, no contexto do SegT, como parte do campo temático abrangido pelo tópico do SegT. Assim, o primeiro tipo de grupo de enunciados e o segundo diferenciam-se entre si por uma oposição entre a expressão mais geral do tópico de um SegT mínimo e um tratamento mais específico desse tópico. Seguindo Penhavel (2010), consideramos o primeiro tipo de grupo de enunciados e o segundo tipo como instâncias de unidades intratópicas que chamaremos de posição e suporte, respectivamente.

Cada grupo de enunciados que funciona como suporte em relação ao SegT mínimo como um todo pode estruturar-se, internamente, também com base na relação posição-suporte. As unidades de posição e de suporte relativas diretamente ao SegT mínimo inteiro podem ser entendidas como posição e suporte de nível 1, e as unidades de posição e de suporte integrantes da estruturação interna de um suporte de nível I podem ser pensadas como posição e suporte de nível 2. Uma posição de nível 2 concentra-se em expressar a temática central do suporte de

\footnotetext{
${ }^{9}$ Esse conjunto de 24 editoriais constitui o que a referida equipe considerou como um corpus mínimo de editoriais paulistas da primeira metade do século XX. Embora reduzido em relação à totalidade de editoriais levantados pelo grupo, esse material procura contemplar textos de uma diversidade considerável de anos, meses e dias, de modo a ser representativo de editoriais da época. O corpus reúne um editorial de cada um dos seguintes dias (com exceção do dia 20/09/1928, que conta com dois editoriais): 27/04/1923, 28/04/1923, 29/04/1923, 09/05/1923, 08/05/1924, 10/05/1924, 28/05/1924, 30/05/1924, 06/06/1925, 09/06/1925, 20/06/1925, 21/06/1925, 16/07/1926, 17/07/1926, 20/07/1926, 22/07/1926, 20/08/1927, 30/08/1927, 03/09/1927, 05/09/1927, 18/09/1928, 19/09/1928, 20/09/1928. Para maiores detalhes sobre o corpus, cf. Almeida (2017).
} 
nível 1 em que se insere, e um suporte de nível 2 dedica-se a desenvolver uma especificação da temática central do suporte de nível I que o comporta. Esse esquema pode aplicar-se por mais níveis de especificação temática, instaurando posições e suportes de níveis 3, 4, 5 etc. Ou seja, a relação posição-suporte constitui um mecanismo recursivo de organização intratópica. O SegT mínimo inteiro e cada suporte internamente estruturado segundo a relação posição-suporte podem ser chamados de diferentes domínios de organização intratópica.

Tendo em vista que o tópico de um SegT mínimo é um tema, assim como também é um tema aquilo que é focalizado em cada suporte (de qualquer nível), pode-se definir posição e suporte de modo um pouco mais amplo do que a forma pela qual, logo acima, introduzimos essas noções, quando foram referidas apenas em relação ao tópico do SegT mínimo, de modo a recobrirmos agora não só a instauração de posições e suportes nesse domínio, mas também a eventual instauração dessas unidades em domínios mais específicos. Assim, a posição pode ser definida como um conjunto de enunciados focado em expressar (sintetizar) um dado tema, e o suporte, como um conjunto de enunciados focado em desenvolver (discorrer sobre) esse tema mediante a focalização do que, no contexto do SegT, é formulado como uma temática mais específica, integrante do campo temático estabelecido na posição. ${ }^{10}$

Posição e suporte são unidades entre as quais podem ser estabelecidos diferentes tipos de relações de sentido. A relação mais comum que um suporte mantém com uma posição é a de elaboração, embora possam verificar-se também outros tipos, como causa, consequência, comparação etc. De todo modo, qualquer que seja a relação de sentido, o que caracteriza os estatutos de posição e suporte é a instauração, no contexto do SegT, de uma oposição entre maior e menor abrangência temática, respectivamente. ${ }^{11}$

Tomando essas noções de posição e suporte, a regra de organização intratópica identificada nos editoriais (a ser definida de modo mais completo adiante) pode ser referida, por ora,

\footnotetext{
${ }^{10}$ Em linha com o que adiantamos na seção anterior, pode-se notar aqui que aplicamos o termo tópico para o referente geral do SegT mínimo (assim como para referentes de SegTs maiores, não mínimos, ou seja, para o nível intertópico), caso em que vale também o termo tema (ou temática). Na organização intratópica, porém, para cada especificação do tópico do SegT mínimo (focalizada em cada suporte), não usamos o termo tópico, mas apenas tema/temática. O tratamento dessas especificações pelo uso do rótulo tópico poderia encaminhar a análise para menções como supertópico e subtópico, noções já especializadas para o nível intertópico. Para evitar essa sobreposição terminológica entre os níveis inter e intratópico (dentre outras complicações de nomenclatura) temos usado, na abordagem deste último (isto é, na abordagem da estruturação interna de SegTs mínimos), apenas o termo tema (e correlatos), mediante menção a grupos de enunciados com maior e menor abrangência temática. Consideramos ser esta uma opção que não implica nenhum comprometimento conceitual e que viabiliza o tratamento prático dos dois níveis. De toda forma, admitimos que uma maior uniformização terminológica poderia representar um enriquecimento para a GTI, tarefa que deixamos para trabalhos futuros.

${ }^{11}$ Referimo-nos aqui à noção de elaboração definida pela Teoria da Estrutura Retórica (MANN; THOMPSON, 1988), abordagem especializada no estudo de relações de sentido entre enunciados. Segundo a teoria, uma relação de elaboração ocorre entre um segmento núcleo e um segmento satélite, quando o satélite expõe detalhes adicionais sobre algum elemento do assunto exposto no segmento núcleo ou acessível inferencialmente no núcleo; na relação de elaboração, considerando qualquer um dos seguintes pares de sentido, se o núcleo expõe o primeiro elemento do par, o satélite expõe o segundo: grupo-membro; abstração-instância; todo-parte; processo-passo; objeto-atributo; generalização-especificação. Para uma articulação teórico-metodológica entre a Teoria da Estrutura Retórica e a GTI, bem como para uma explicitação da compatibilidade entre ambas, ver Souza (2020).
} 
como sendo um padrão que prediz a construção de SegTs mínimos por meio da combinação, potencialmente recursiva, entre unidades de posição e unidades de suporte. ${ }^{12}$

O SegT mínimo em (1) acima, retomado em (2), organiza-se conforme essa regra:

(2) Assume proporções verdadeiramente alarmantes a quantidade de pernilongos que 1 actualmente infestam a nossa capital.

Não ha memoria de uma invasão assim consideravel e assustadora desses insectos, tão 3 perigosos vehiculos e propagadores de enfermidades graves. S. Paulo jamais se conheceu 4 completamente livre desses incommodos hospedes, é bem verdade: mas nunca se registou a 5 sua presença em quantidades tão prodigiosas como agora acontece. Não haverá um 6 habitante desta capital que tenha já ouvido falar, mesmo de quando havia pantanos e 7 brejos dentro do perimetro urbano, de uma invasão igual á desses sanguisedentos 8 mosquitos que actualmente dominam a cidade.

Quer de dia, quer de noite, nos cafés, nas lojas, nos theatros, nos escriptorios, nas ruas, 10 nas praças, nos hoteis, nas residencias, onde quer que alguem se ponha mais ou menos 11 immovel por um minuto ou dois, la o vao assaltar um exercito dos trombeteantes 12 culicideos, que o ferrotoam, que lhe sugam o sangue, que lhe innoculam germens de toda 13 casta, deixando-lhe na pelle a marca inconfundivel das suas façanhas (O Estado de S. Paulo, 14 27/04/1923, grifos nossos).

O tópico desse SegT pode ser sintetizado como Proporções alarmantes da invasão de pernilongos na cidade de São Paulo, já que é plausível interpretar esse tema como aquele que seria o mais particular possível, mas, ao mesmo tempo, abrangente o bastante para ser reconhecido como um tema focalizado em todo o segmento, em relação ao qual todos os enunciados seriam concernentes. $\mathrm{O}$ foco e a concernência em torno dessa temática podem ser notados, por exemplo, pelo emprego das seguintes expressões, distribuídas no decorrer do SegT: "proporções verdadeiramente alarmantes" (já na linha 1, referindo-se à quantidade de pernilongos na cidade), "uma invasão assim consideravel e assustadora desses insectos”, "a sua presença em quantidades tão prodigiosas", "uma invasão igual á desses sanguisedentos mosquitos que actualmente dominam a cidade" (nas linhas intermediárias 3, 5-6 e 8-9, respectivamente) e "um exercito dos trombeteantes culicideos" (nas linhas mais finais 12-13).

Assumindo que seja esse o tópico do SegT, é possível notar que o enunciado nas linhas 1 e 2 concentra-se em expressar esse tópico, referindo-se diretamente à proporção alarmante da invasão de pernilongos. Já os demais enunciados focalizam o desenvolvimento de temáticas

\footnotetext{
${ }^{12} \mathrm{~A}$ regra que descrevemos aqui é semelhante à que identificamos em relatos de opinião (cf. PENHAVEL, 2010) e à observada em editoriais paulistas do início do século XXI (cf. GARCIA, 2018), podendo até ser interpretada como a mesma regra geral apurada nesses outros trabalhos. Porém, não chegamos a sintetizar aqui as descrições feitas nesses outros trabalhos, nem as comparamos com nossa análise. Por ora, optamos por descrever detalhadamente a regra observada em nossos editoriais novecentistas, inclusive porque, nesses três materiais, embora as regras gerais possam ser semelhantes/iguais, há diferenças significativas quanto a suas implementações. Deixamos, assim, para trabalho posterior a análise comparativa, seja entre editoriais e outros gêneros, seja entre editoriais de diferentes sincronias.
} 
que, conforme formuladas, especificam esse tópico. Da linha 3 à 9, focaliza-se a superioridade da invasão em relação a outras na história da cidade, o que seria um traço (dentre outros possíveis) do caráter alarmante da invasão, tópico do SegT, sendo, pois, uma temática integrante desse tópico. Similarmente, da linha 10 à 14, é focalizada a grande amplitude espacial e temporal da invasão, que seria também um traço particular do estado alarmante da invasão. Desse modo, as linhas 1-2 constituem uma unidade de posição, as linhas 3-9 formam um primeiro suporte, e as linhas 10-14, um segundo suporte. ${ }^{13}$

Em termos mais detalhados, a regra geral aqui em questão prediz a forma de organização intratópica que pode ser expressa em (3):

(3) Regra geral de organização intratópica:

O SegT mínimo (e, potencialmente, cada unidade de suporte): deve conter uma unidade de posição, antecedida de nenhum, um ou mais de um suporte, e seguida por nenhum, um ou mais de um suporte (sendo obrigatório pelo menos um suporte, antes ou depois dessa primeira posição); contendo, após a primeira posição, um ou mais de um suporte, pode conter, após esse(s) suporte(s), uma segunda unidade de posição. ${ }^{14}$

Essa regra permite a organização de SegTs mínimos (e de suportes) conforme vários encadeamentos diferentes, como suporte-posição, suporte-suporte-posição, posição-suporte, posição-suporte-suporte (caso do SegT em (2)), posição-suporte-posição,

\footnotetext{
${ }^{13}$ As noções de posição e suporte normalmente equivalem, respectivamente, ao que se pode considerar como tese e argumento. Essa identificação certamente está ligada à natureza argumentativa do gênero editorial e, enfim, à modalidade argumentativa de construção textual, considerada como uma das modalidades de construção textual, ao lado, por exemplo, da modalidade narrativa, no sentido assumido, dentre outros autores, por Schiffrin (1987). A propósito, a autora reconhece as categorias que nomeia justamente de posição e suporte como base da modalidade argumentativa do discurso, e é com inspiração nessa autora que adotamos os referidos termos. No entanto, em nosso trabalho, não vinculamos diretamente essas noções à modalidade argumentativa, em termos de tese-argumento, mas à dimensão da organização tópica, mediante a oposição entre maior e menor abrangência temática, como forma de preservar o vínculo da nossa análise com a dimensão da organização tópica do texto e porque, nem sempre, posição e suporte, em termos tópicos, equivalem a tese e argumento (a esse respeito, cf. Valli (2017), que descreve suportes que funcionam como contextualização, e não como argumentação, para o tópico do SegT). De todo modo, a relação entre a dimensão tópica do texto e a modalidade argumentativa merece uma discussão pormenorizada em trabalho específico para esse fim.

${ }^{14}$ No presente trabalho, na sistematização da regra, em (3), optamos por, em parte, limitar e, em parte, deixar ilimitada a diversidade de combinações possíveis entre unidades de posição e suporte. Deixamos em aberto a quantidade máxima de suportes que podem ocorrer antes e depois da primeira posição. Como será relatado mais adiante, encontramos, em nosso material, dentre outras estruturas, domínios com um, dois, quatro e cinco suportes após a primeira posição. $\mathrm{O}$ encadeamento de três suportes (em sendo uma quantidade abaixo de dois tipos empiricamente atestados - quatro e cinco suportes) certamente é possível, não tendo ocorrido no material apenas por acaso. Sequenciamentos de seis, sete, oito suportes também parecem previsíveis, com base na sequência atestada de cinco suportes. Mas o estabelecimento de algum limite para esse encadeamento (nove, dez, quinze suportes) requereria a análise de um corpus mais extenso. Já em relação à quantia de posições, pareceu-nos possível e pertinente identificar o limite máximo de duas ocorrências. Enquanto uma posição sempre ocorre por domínio, a presença de duas já é bem pouco produtiva (tendo incidência baixa, como relatado adiante), parecendo ser um limite máximo do que seria o padrão do gênero (três ou mais posições por domínio não ocorreram no material analisado). Seja como for, reconhecemos a relevância de reunir um corpo maior de dados que mostre a variabilidade prevista pela regra. No entanto, entendendo este trabalho apenas como uma etapa de um percurso de pesquisa ainda em desenvolvimento, reservamos esse tipo de postulação para trabalho futuro.
} 
posição-suporte-suporte-posição, suporte-posição-suporte, dentre outros. Em qualquer encadeamento possível, a regra envolve, no máximo, três tipos de diferenciação entre unidades: (i) envolve, necessariamente, a diferenciação entre a categoria de posição e a de suporte (na medida em que prevê sempre, pelo menos, uma unidade de cada uma dessas categorias); (ii) pode envolver também a diferenciação entre dois ou mais suportes; (iii) pode ainda envolver a diferenciação entre duas posições.

O primeiro tipo de distinção ancora-se na própria oposição de abrangência temática que define as categorias de posição e suporte, podendo ser notado no SegT em (2), em que se vê a oposição entre uma referência direta ao caráter alarmante da invasão de pernilongos versus o tratamento específico de traços desse caráter.

O segundo tipo de distinção (entre dois ou mais suportes) baseia-se na instauração, no interior de cada um deles, do que se pode considerar como uma centração própria, mais específica do que uma centração mais geral que integra os suportes entre si e que os integra com sua(s) posição(ões) (uma "subcentração" própria) - ou seja, verifica-se maior proximidade de sentido entre enunciados de um mesmo suporte do que entre enunciados de suportes diferentes. Ademais, tais suportes caracterizam-se por manterem entre si uma relação de equipolência tópica (não há hierarquização entre eles em termos de abrangência temática), estando igualmente subordinados à(s) mesma(s) posição(ões).

É exatamente o que se verifica entre os dois suportes distinguidos em (2). Como mencionado, o trecho nas linhas 3-9 focaliza a superioridade da invasão de pernilongos em relação a outras anteriores. Todos os enunciados desse trecho tratam diretamente dessa questão, o que fica evidente pelas partes em negrito na reprodução do SegT, sobretudo pelas passagens "Não ha memoria de uma invasão assim", "nunca se registou a sua presença em quantidades tão prodigiosas" e "Não haverá um habitante desta capital que tenha já ouvido falar [...] de uma invasão igual", que são claramente concernentes entre si e colocam em foco a ausência de registro histórico de uma invasão nas proporções daquela em pauta. Já a partir da linha 10, é tirada de foco a comparação histórica, cessando-se completamente menções a essa temática. O foco passa a incidir desta vez sobre o alcance da invasão, em termos temporais e espaciais, alcance manifestado por um conjunto de referências concernentes entre si, organizadas em torno dessa nova temática, não abordada no bloco anterior da linha 3 à 9. Essas formas de alcance manifestam-se pelos circunstanciadores "quer de dia, quer de noite" e "onde quer que alguem se ponha", indicativos de certa noção de completude, temporal e espacial respectivamente, sendo o segundo ainda antecedido por uma listagem de referências locativas: "nos cafés", "nas lojas", "nos theatros", "nos escriptorios" etc. Nota-se, pois, que as unidades analisadas em (2) como dois suportes compartilham uma centração mais geral acerca do caráter alarmante da proporção da invasão de pernilongos, mas, no âmbito dessa circunscrição temática, cada uma particulariza-se por uma centração mais específica própria. 
Ou seja, verifica-se maior proximidade de sentido entre o enunciado (do primeiro suporte) segundo o qual "Não ha memoria de uma invasão assim [...]" e o enunciado (também do primeiro suporte) de acordo com o qual "[...] nunca se registou a sua presença em quantidades tão prodigiosas [...]”, do que entre qualquer um deles e o enunciado (do segundo suporte) pelo qual se diz que, "Quer de dia, quer de noite [...] onde quer que alguem se ponha [...] la o vao assaltar um exercito dos trombeteantes culicideos".

O SegT em (2) mostra, ainda, que a diferenciação entre dois (ou mais) suportes de um mesmo domínio de organização intratópica significa reconhecê-los como tematicamente equipolentes entre si e igualmente subordinados à(s) mesma(s) posição(ões). Em (2), o alcance temporal e espacial da invasão (foco do fragmento nas linhas 10-14) não seria uma especificação temática da superioridade histórica da invasão (foco do excerto nas linhas 3-9). Uma especificação da temática dessa superioridade seria eventualmente uma abordagem da proporção de uma invasão ocorrida na década anterior, uma discussão acerca da primeira invasão registrada na história etc. Mas o alcance temporal e espacial da invasão seria uma especificação de seu caráter alarmante (tema expresso na posição nas linhas 1-2), assim como também o seria a sua superioridade histórica.

É nesse sentido que consideramos que o reconhecimento de dois ou mais grupos de enunciados como diferentes suportes dentro de um mesmo domínio depende (i) da instauração, em cada um, de uma centração mais específica própria, relativamente àquela que une esses suportes entre si e que os une a sua(s) posição(ões), e (ii) da possibilidade de interpretação de que esses grupos sejam tematicamente equipolentes entre si.

O SegT mínimo em (4) também ilustra a regra em análise, permitindo observar novamente o primeiro e o segundo tipos de distinção entre unidades intratópicas, na medida em que contém, a exemplo do SegT em (2), uma posição (linhas 1-3) seguida de dois suportes (linhas 4-8 e 9-12):

(4) Appareccida entre nós a terrível praga da broca do café, fomos dos que confiaram em que São 1 Paulo saberia enfrentar corajosamente mais esse inimigo da sua riqueza máxima, 2 promovendo, por todos os meios ao seu alcance, a sua extincção. E não nos enganâmos. 3

Comprehendendo a importancia e a urgencia do problema, que implicava a propria 4 estabilidade economica do Estado, os poderes públicos logo se puzeram a campo, 5 congregando os esforços dos interessados e chamando, para os orientar, technicos 6 competentes, a quem facultou todos os meios para estudar a praga e aconselhar as 7 medidas mais efficazes para a combater.

Demonstrando o seu empenho em secundar a acção do Executivo, dando base legal aos actos 9 necessarios ao completo êxito da campanha, o Congresso do Estado apparelhou o governo 10 com a legislação que para esse fim se fazia mister, elaborando a lei n. 2.020, de 20 de 11 Dezembro de 1924 (O Estado de S. Paulo, 09/06/1925, grifos nossos). 
Seguindo o mesmo raciocínio exposto acima sobre o exemplo em (2), pode-se nomear o tópico do SegT em (4) como Enfrentamento corajoso do problema da broca do café por parte do estado de São Paulo. As linhas 1-3 concentram-se na expressão desse tópico, como se vê especialmente pelas passagens em negrito, constituindo por isso uma posição. O restante do SegT desenvolve esse tópico, focalizando duas ações particulares integrantes do referido enfrentamento corajoso: o recrutamento de técnicos para tratar do problema, nas linhas 4-8, e a elaboração de legislação apropriada para enfrentamento do problema, nas linhas 9-12. Esses trechos compõem, assim, duas unidades de suporte.

Para observação do terceiro tipo de distinção entre unidades intratópicas (a diferenciação entre duas posições de um mesmo domínio), veja-se o SegT mínimo abaixo, que contém uma posição (linhas 1-5), três suportes (linhas 6-9, 10-12, 13-17) e, então, uma segunda unidade de posição (linhas 18-19):

(5) Antetãoboas disposições, edadooêxitoquevem coroandoaacçãodiligentedaCommissão, deve 1 o governo exercer a maxima severidade no intuito de ter completa execução o serviço de 2 expurgo, compellindo, pelos meios legaes dequeseachamunido, atodosos queaindavacillarem, 3 a concorrer com o seu contingente pessoal para o bom resultado da campanha em tão boa 4 hora iniciada.

Toda energia posta nesse proposito terse-á por excellentemente empregada e justa, pois 6 não será mais preciso repetir-se que o que está em jogo - a lavoura cafeeira paulista - é 7 um patrimonio para cuja defesa importa que todos os esforços sejam dirigidos para o fim 8 vigado, sem discrepancia de nenhum.

É agora, na applicação das medidas aconselhadas pelos technicos que tão 10 competentemente se puzeram em campo, para salvar os cafesaes de S. Paulo, que se torna 11 necessaria toda firmeza e decisão, por parte do governo e dos lavradores.

Do contrario, seria perder-se todo o effeito já dispendido, como o bem avisado 13 movimento com que o Congresso, patrioticamente deu o seu concurso para se enfrentar, com 14 probabilidade de exito, a emminencia do perigo apresentado pela broca, e o patriotismo da 15 maioria dos lavradores que desde logo compreenderam estar o seu proprio interesse no apoio 16 que dessem á acção official.

O expurgo systematico de todo café em côco nas zonas contaminadas, deve tornar-se uma 18 pratica corrente e uniforme em todas as fazendas [ininteligível] (O Estado de S. Paulo, 19 09/06/1925, grifos nossos).

Considerando o tópico desse SegT como A necessidade de realização completa do serviço de expurgo do café, pode-se reconhecer as linhas 1-5 e 18-19 como duas unidades de posição, ao focalizarem a expressão desse tópico. Já as linhas 6-9, 10-12 e 13-17 constituem três suportes por especificarem esse tema, focalizando três justificativas para o referido serviço de expurgo, respectivamente, a importância do café para o estado de São Paulo, a necessidade da aplicação das 
medidas aconselhadas pelos técnicos e a perda de efeitos positivos já alcançados, no caso de não realização do serviço de expurgo.

Como ilustra o SegT em (5), a diferenciação entre duas posições de um mesmo domínio verifica-se quando, após uma posição seguida de um (ou mais de um) suporte, o domínio contém um novo conjunto de enunciados cujo foco parafraseia o que está focalizado na posição anterior. Ou seja, duas posições, no que se refere à expressão do tema nuclear do domínio, serão sempre (i) parafrásticas e (ii) não-adjacentes entre si.

Para notar essas duas condições, é necessário atentar-se para o fato de que cada domínio contém um único tema geral, bem como para a definição de posição, que a estabelece como uma unidade que expressa o tema geral de um domínio. ${ }^{15}$

Sendo assim, para que diferentes grupos de enunciados possam constituir diferentes unidades de posição dentro de um mesmo domínio, devem focalizar a expressão de uma mesma ideia básica, aquela que é o tema do domínio, podendo diferir apenas nas palavras usadas, ou seja, devem ser parafrásticas entre si (assumimos aqui a concepção de paráfrase desenvolvida em Hilgert (2006)). Trata-se de uma situação distinta do que se verifica com diferentes suportes de um mesmo domínio. Os suportes, na medida em que focalizam temáticas específicas em relação ao tema geral do domínio, diferenciam-se uns dos outros justamente pelo fato de cada um focalizar uma temática particular. Mas o tema geral de um domínio é apenas um, e, assim, diferentes grupos de enunciados só poderão ser diferentes unidades de posição se focalizarem a expressão desse mesmo e único tema.

No mesmo sentido, na progressão do encadeamento de enunciados para construção de um domínio, enquanto uma dada sequência de enunciados ainda se concentra na expressão do tema do domínio, não há razão para dividi-la em duas ou mais partes tópicas, já que o grau de abrangência temática continuaria o mesmo. Desse modo, não seria pertinente reconhecer duas unidades de posição adjacentes entre si. Ou seja, só é possível reconhecer duas unidades de posição se entre elas houver um, ou mais de um, suporte, como captado na regra sintetizada em (3) e como ilustrado em (5). ${ }^{16}$

\footnotetext{
${ }^{15}$ Para reconhecer que um domínio contém um único tema geral, pode-se pensar, por exemplo, no próprio SegT mínimo como um todo, que necessariamente tem um único tema mais geral (o seu tópico). Note-se que, se um dado segmento textual que a princípio possa parecer um SegT mínimo focaliza dois temais centrais, igualmente relevantes entre si num dado texto, então esse segmento textual terá de abranger, na verdade, dois SegTs mínimos, e não apenas um; ou o segmento textual seria, de fato, um único SegT mínimo, mas os dois temas aparentemente centrais seriam, na verdade, duas especificações de um tema ainda mais geral (este, sim, o tópico do SegT mínimo), comum aos dois temas a princípio pensados como centrais. Como se vê, por definição, um SegT mínimo (e, do mesmo modo, qualquer outro domínio) terá sempre um único tema geral.

${ }^{16}$ Embora não tenhamos encontrado nenhum caso do tipo em nossos dados, seria possível pensar num domínio que contivesse um conjunto de enunciados expressando o tema do domínio, já seguido de um segundo conjunto parafrástico de enunciados (ocorrendo o(s) suporte(s) apenas depois da paráfrase). Nesse caso, poder-se-ia pensar que estariam ocorrendo duas posições adjacentes. No entanto, numa situação desse tipo, não consideraríamos os dois conjuntos de enunciados como duas unidades diretamente integrantes da estrutura do domínio. Entenderíamos o bloco todo formado pelos dois conjuntos como sendo uma unidade de posição na estrutura do domínio, e a distinção entre os dois conjuntos seria tratada no nível da estruturação interna dessa posição (um nível de análise, porém, ao qual não chegamos neste trabalho, até mesmo pela não ocorrência de dados empíricos a esse respeito em nosso material).
} 
Ambas as condições para a ocorrência de duas posições em um domínio - o relacionamento parafrástico e não-adjacente - podem ser identificadas em (5). A não-adjacência fica evidente pela ocorrência de três suportes entre as duas posições distinguidas.

Já para o reconhecimento da relação parafrástica, é preciso ressaltar um traço das unidades de posição e suporte (que consideramos em suas definições, embora ainda não o tenhamos ressaltado) que é o fato de elas se definirem em termos do que elas focalizam. Posição e suporte, normalmente, não se referem exclusivamente (ou apenas de forma direta) a um dado tema. Na verdade, essas unidades referem-se principalmente, predominantemente, a um tema, mas podem também conter referências secundárias (ou se referir ao tema focalizado de forma indireta). Essa predominância de referência é o que procuramos descrever pela ideia de que essas unidades focalizam um tema - focalizam a expressão geral do tema de um domínio, no caso da posição, e focalizam uma especificação desse tema, no caso do suporte.

Por exemplo, em (5), a primeira posição faz, dentre outras, referência ao que chama de "boas disposições" e ao que considera como "êxito que vem coroando a acção diligente da Commissão", remetendo a questões tratadas em parte anterior do editorial. Essas entidades, é claro, estão relacionadas à necessidade do serviço de expurgo do café, e as expressões que as referem integram o próprio enunciado que remete ao serviço de expurgo. Todavia, a referência a essas entidades exerce aí um papel acessório, secundário, subsidiário. A continuidade do SegT, até seu final, vai definindo que o que está em primeiro plano é a questão da necessidade do serviço de expurgo, e não as boas disposições ou o êxito da referida comissão. Assim, a primeira posição do SegT em (5) (bem como a segunda) se caracteriza pela referência à necessidade de serviço de expurgo, embora essa referência possa estar acompanhada de outras acessórias (ou indiretas).

O mesmo ocorre na posição do SegT em (4). A unidade evoca a confiança dos editores do jornal de que São Paulo enfrentaria corajosamente o problema da broca do café ("fomos dos que confiaram", "não nos enganâmos"). Mas claramente a continuidade do SegT não desenvolve essa temática, e sim a postura do estado frente ao problema, sendo a referência a essa postura o que fica em foco na posição e a caracteriza como tal. Pode também ocorrer de (quase) todas as palavras da posição estarem diretamente ligadas à expressão do que está em foco na unidade, o que se vê na posição do SegT em (2), mas essa exclusividade de referência não seria uma condição para a formulação de uma unidade intratópica.

Em suma, posição e suporte caracterizam-se não em termos da exclusividade, mas da relevância de referência a um tema no contexto do domínio, propriedade que procuramos prever mediante a definição dessas unidades em termos da focalização de um tema.

É considerando esse traço das unidades intratópicas que entendemos o relacionamento parafrástico como uma condição para a distinção entre duas unidades de posição de um domínio, isto é, a paráfrase entre posições incide não necessariamente entre as posições inteiras, mas entre suas partes que (mais diretamente) remetem ao tema central do domínio. 
No caso das posições do SegT em (5), a paráfrase seria perceptível entre as seguintes passagens, respectivamente da primeira e da segunda posição: “[...] deve o governo exercer a maxima severidade no intuito de ter completa execução o serviço de expurgo" e "O expurgo systematico de todo café em côco [...] deve tornar-se uma pratica corrente e uniforme em todas as fazendas [...]".

A identidade de sentido entre essas passagens manifesta-se não só pela própria referência global de cada passagem ao tópico do SegT, mas também por conexões particulares explícitas entre elas e decisivas para o estabelecimento do tópico. Observa-se a repetição do substantivo "expurgo", que, embora central na formulação do tópico, só aparece nessas passagens das posições, não ocorrendo em nenhum dos suportes. Nota-se também a repetição da forma verbal deôntica "deve", crucial na instauração da ideia de necessidade do serviço de expurgo - a propósito, é interessante notar que a noção de necessidade, embora latente nos três suportes, não é referida nessas unidades pelo verbo dever, que, também aparecendo apenas nas duas passagens em pauta (igualmente ao que ocorre com o substantivo "expurgo"), contribuiria para criação da identidade entre elas. Ademais, verifica-se, nas duas passagens, a referência comum à noção de completude do serviço de expurgo, evocada, na primeira passagem, pela expressão "completa execução do serviço de expurgo" e, na segunda, pelas expressões "o expurgo systematico de todo café em côco" e "prática corrente e uniforme em todas as fazendas" (grifos nossos).

São, enfim, evidências desse tipo, juntamente com o entendimento da posição em termos de focalização de um tema, que permitem reconhecer a identidade parafrástica entre duas partes de um domínio, a qual junto com a condição de não-adjacência definem a possibilidade de reconhecimento de duas unidades de posição em um domínio.

Conforme deve ter ficado evidente na discussão até aqui, a noção de domínio é fundamental na organização intratópica dos editoriais em análise. Como explicado, um domínio se instaura sempre que a relação posição-suporte organiza uma parte do SegT mínimo, o que se aplica ao SegT inteiro e possivelmente a unidades de suporte, por recursividade da regra. A instauração de domínios pode ser visualizada no SegT mínimo em (6) (na linha 2, a expressão "semelhante ameaça" refere-se à invasão de pernilongos introduzida no SegT em (2)): 
(6) Entretanto, nãosabemosaindadenenhuma providenciaquetenhasidosequeralvitradapara 1 livrar a nossa população paulistana de semelhante ameaça. 2

Ao que nos consta, o Serviço Sanitário do Estado, ao qual naturalmente se voltam todos os 3 espiritos á espera das providencias que está a pedir o caso, attribue-se completa 4 impossibilidade de acção, em vista de dependerem taes providencias da iniciativa dos 5 poderes municipaes e da Repartição de Aguas. 6

Destes ultimos nada sabemos; mas o que se póde deduzir do silencio em que se mantém a 7 respeito do assumpto, é que muito pouco se estão preoccupando com elle. 8 Queixa-se a autoridade sanitaria do mau estado em que a Repartição de 9 Aguas deixa que perdurem as installações de esgotos, em certos bairros, 10 como a Barra Funda, o que constitue um dos fócos de proliferação dos 11 perigosos e incommodos insectos.

Aos poderes municipaes caberão talvez ainda maiores responsabilidades no caso, 13 pois é facil de ligar a presente invasão de mosquitos á ultima enchente dos rios que 14 atravessam o municipio da capital. 15 Inundadas as varzeas e nellas depositada toda sorte de detrictos vehiculados 16 pela corrente, ellas se transformam, em seguida, quando os rios readquirem o 17 volume normal, em vastissimos viveiros de onde enxameiam os pernilongos 18 a martyrisar a população (O Estado de S. Paulo, 27/04/1923, grifos nossos). 19

De acordo com nossa leitura, o tópico desse SegT mínimo seria A ausência de providências quanto à invasão de pernilongos. Assim sendo, pode-se reconhecer, no domínio da organização intratópica do SegT inteiro, uma unidade de posição formada pelas linhas 1 e 2, em que esse tópico é expresso, e uma unidade de suporte formada por todo o restante do SegT, da linha 3 à 19, que desenvolve o tópico, focando a impossibilidade de ação, por parte do Serviço Sanitário do Estado, devido a problemas nos poderes municipais e na Repartição das Águas, temática que trata das causas da ausência de providências, sendo assim uma forma particular (dentre outras possíveis) de abordar o tópico do SegT.

Esse suporte disposto no bloco da linha 3 à 19 organiza-se internamente também com base na relação posição-suporte. O fragmento nas linhas 3-6 concentra-se em expressar a temática de todo o bloco, que, como mencionado, trata da impossibilidade de ação por causa dos poderes públicos e da Repartição das Águas. Na sequência, as linhas 7-12 tratam de um desses elementos e as linhas 13-19, do outro, constituindo, pois, dois suportes relativos à posição formada pelas linhas 3-6.

Novamente mediante o mecanismo da recursividade, cada um desses dois suportes também se organiza internamente pela relação posição-suporte. O excerto nas linhas 7-12 enfoca a pouca preocupação da Repartição das Águas quanto à invasão de pernilongos. As linhas 7-8 expõem essa temática, e as linhas 9-12 a especificam, reportando-se ao alegado mau estado em que a Repartição das Águas teria deixado as instalações de esgotos em certos bairros, gerando focos de 
proliferação de pernilongos, o que seria uma instanciação concreta da referida pouca preocupação da repartição. O trecho nas linhas 13-19, por sua vez, aborda a responsabilidade dos poderes municipais devido às enchentes dos rios da cidade. Nesse âmbito, as linhas 13-15 introduzem essa questão, e as linhas 16-19 a desenvolvem, esclarecendo o modo como as enchentes fomentam a invasão de pernilongos.

Cada reaplicação da relação posição-suporte dentro de um suporte, gerando novas unidades de posição e suporte, instaura, então, o que chamamos de domínio de organização intratópica. Cada domínio é um âmbito próprio de manutenção de relações entre posição e suporte na construção do SegT mínimo, podendo ser definido como uma unidade formada por uma posição (ou por duas posições que focalizem a expressão do mesmo tema) e seu(s) suporte(s). Os quatro domínios instaurados no SegT em (6) podem ser assim sintetizados:

a) domínio 1 (linhas 1-19):

- posição (linhas 1-2): A ausência de providências quanto à invasão de pernilongos;

- suporte (linhas 3-19): A impossibilidade de ação, por parte do Serviço Sanitário do Estado, devido a problemas nos poderes municipais e na Repartição das Águas.

b) domínio 2 (linhas 3-19):

- posição (linhas 3-6): A impossibilidade de ação, por parte do Serviço Sanitário do Estado, devido a problemas nos poderes municipais e na Repartição das Águas;

- suporte (linhas 7-12): A pouca preocupação da Repartição das Águas quanto à invasão de pernilongos; - suporte (linhas 13-19): A responsabilidade dos poderes municipais devido às enchentes dos rios da cidade.

c) domínio 3 (linhas 7-12):

- posição (linhas 7-8): A pouca preocupação da Repartição das Águas quanto à invasão de pernilongos; - suporte (linhas 9-12): O mau estado em que a Repartição das Águas teria deixado as instalações de esgotos em certos bairros gerando focos de proliferação de pernilongos.

d) domínio 4 (linhas 13-19):

- posição (linhas 13-15): A responsabilidade dos poderes municipais devido às enchentes dos rios da cidade; - suporte (linhas 16-19): O modo como as enchentes fomentam a invasão de pernilongos.

A apreensão (tanto pelo falante, quanto pelo analista) da estruturação do SegT mínimo em domínios é relevante, uma vez que é no âmbito de um domínio, e não no âmbito propriamente do SegT como um todo, que grupos de enunciados assumem um estatuto tópico, no caso, os estatutos de posição e suporte. Em (6), por exemplo, o trecho nas linhas 7-12 assume estatuto tópico de suporte na circunscrição do trecho nas linhas 3-19, não no âmbito do SegT inteiro. Ou seja, o trecho nas linhas 7-12 não constituiria diretamente uma parte do SegT, mas seria uma parte do fragmento nas linhas 3-19-este sim, nas linhas 3-19, é que constituiria uma parte propriamente do SegT, no caso, um suporte.

Em síntese, nesta seção, relatamos a existência de uma regra geral de organização intratópica nos editoriais em análise, definimos as unidades envolvidas e explicamos o 
funcionamento da regra. Para completar o trabalho, expomos, a seguir, dados quantitativos acerca de dois aspectos da efetivação da regra no material analisado, apenas com o propósito de disponibilizar dados que, juntamente com a própria descrição da regra, possam ser comparados, em outros trabalhos, com dados de editoriais de outras sincronias.

O Quadro 1 mostra as diferentes quantidades de domínios por SegT mínimo no material analisado, bem como os percentuais de cada quantia:

Quadro 1: Quantidade de domínios por segmento tópico mínimo.

\begin{tabular}{|c|c|}
\hline Quantidade de domínios por SegT mínimo & $\begin{array}{c}\text { Percentuais de ocorrência em relação ao total de } \\
\text { SegTs mínimos }\end{array}$ \\
\hline 1 & $63 \%$ (41 de 65 SegTs mínimos) \\
\hline 2 & $26 \%$ (17 de 65 SegTs mínimos $)$ \\
\hline 3 & $3 \%$ (2 de 65 SegTs mínimos) \\
\hline 4 & $8 \%$ (5 de 65 SegTs mínimos) \\
\hline
\end{tabular}

Fonte: elaboração própria.

Como relatado anteriormente, em nossa pesquisa identificamos 65 SegTs mínimos cuja organização intratópica segue a regra geral da relação posição-suporte. O Quadro 1 mostra que, em $63 \%$ desses casos ( 41 exemplares), o SegT compreende um único domínio (que consiste na organização do próprio SegT como um todo), em $26 \%$ dos casos (17/65 exemplares), cada SegT contém dois domínios e assim por diante.

A diversidade de tipos de SegTs, em termos da quantidade de domínios que exibem, e a predominância de tipos podem ser indicativas de maior ou menor grau de complexidade intratópica caracterizadora do gênero numa dada sincronia. Como se pode ver, predominam expressivamente, nos editoriais aqui analisados, SegTs com apenas um domínio, havendo uma incidência média de SegTs com três domínios e baixa incidência de SegTs com três e quatro domínios. Parece tratar-se de um baixo grau de complexidade intratópica, sobretudo em comparação com o que se observa, por exemplo, em editoriais do século XXI, conforme descritos em Garcia (2018), nos quais seria muito mais comum a instauração de mais de um domínio em cada SegT mínimo (que ocorreria em 62,67\% dos SegTs analisados pela autora, compreendendo, inclusive, SegTs com cinco domínios).

Tais dados permitem formular a hipótese de que, na história do editorial de jornal, uma possível alteração seria a ocorrência de um considerável aumento de complexidade de organização intratópica. Trata-se de um tipo de hipótese que pode ser levantada a partir da descrição aqui oferecida e da breve comparação com dados do século XXI, cuja verificação implica ainda a observação de outras sincronias, bem como a avaliação de correlações entre dados da organização intratópica e outras informações sobre o percurso histórico do gênero. 
O Quadro 2 apresenta as diferentes formas de encadeamento entre posição e suporte encontradas nos domínios, no material analisado, e respectivos percentuais de ocorrência:

Quadro 2: Formas de encadeamento entre posição e suporte por domínio de organização intratópica.

\begin{tabular}{|c|c|}
\hline Forma de encadeamento dentro do domínio & $\begin{array}{c}\text { Percentuais de ocorrência em relação } \\
\text { ao total de domínios }\end{array}$ \\
\hline posição-suporte & $45,5 \%$ (46 de 101 domínios) \\
\hline posição-suporte-suporte & $23,5 \%$ (24 de 101 domínios) \\
\hline posição-suporte-suporte-suporte-suporte & $2 \%$ (2 de 101 domínios) \\
\hline posição-suporte-suporte-suporte-suporte-suporte & $5 \%$ (5 de 101 domínios) \\
\hline posição-suporte-posição & $5 \%$ (5 de 101 domínios) \\
\hline posição-suporte-suporte-suporte-posição & $2 \%$ (2 de 101 domínios) \\
\hline suporte-posição & $5 \%$ (5 de 101 domínios) \\
\hline suporte-suporte-posição & $2 \%$ (2 de 101 domínios) \\
\hline suporte-posição-suporte & $10 \%$ (10 de 101 domínios) \\
\hline
\end{tabular}

Fonte: elaboração própria.

Os 65 SegTs mínimos de nossa pesquisa resultam em 101 domínios de organização intratópica. ${ }^{17} \mathrm{O}$ Quadro 2 informa que, desse total, 45,5\% (46 domínios) contêm uma unidade de posição seguida de um suporte, 23,5\% (24 domínios) são formados por uma posição seguida de dois suportes e assim por diante.

Como se vê, o encadeamento posição-suporte é amplamente predominante, o que pode também apontar para certo baixo grau de complexidade intratópica. Nesse caso, porém, novamente sob breve visada nos dados do século XXI, o que se notaria seria uma manutenção diacrônica de padrão, já que, segundo Garcia (2018), também predomina nessa sincronia a sequência posição-suporte, com a frequência, aliás, de 42,39\%, muito parecida com a que apuramos. Cabe discutir, pois, dentre outras questões, o que representaria a possível alteração diacrônica sugeria pelo Quadro i e a possível manutenção indicada pelo Quadro 2, e como as duas tendências estariam relacionadas entre si, indicando traços do percurso diacrônico da organização intratópica dos editoriais. Também aqui, trata-se de questões sobre as quais o presente trabalho pretende apenas fornecer material para futura averiguação.

\section{CONSIDERAÇÕES FINAIS}

Neste trabalho, analisamos a organização intratópica de editoriais do jornal O Estado de S. Paulo da primeira metade do século XX. Procuramos demonstrar que esses textos seguem

\footnotetext{
${ }^{17}$ Essa soma pode ser depreendida do próprio Quadro 1 anterior: 41 SegTs com 1 domínio cada (totalizando 41 domínios), 17 SegTs com 2 domínios cada (34 domínios), 3 SegTs com 2 domínios cada um (6 domínios) e 5 SegTs com 4 domínios cada (20 domínios).
} 
uma regra geral que prevê a construção de SegTs mínimos mediante a combinação potencialmente recursiva de unidades de posição e suporte, sendo a posição um conjunto de enunciados focado em expressar um dado tema, e o suporte, um conjunto de enunciados focado em desenvolver uma temática mais específica, integrante do tema expresso na posição.

Como explicado inicialmente, o trabalho procura contribuir para a teorização acerca do processo de organização intratópica e para o estudo histórico do português brasileiro. Quanto ao primeiro caso, os resultados aqui apresentados apontam para a confirmação da hipótese da sistematicidade da organização intratópica. A regra aqui descrita, a propósito, é bastante representativa da regularidade desse processo. Como mostramos, a combinação entre posição e suporte permite a construção de SegTs segundo uma grande diversidade de configurações. Considerando que esse mecanismo disponibiliza essa diversidade de configurações também para a estruturação interna de cada suporte (recursivamente), a variedade de possíveis formatações de SegTs multiplica-se ainda mais. Porém, toda essa diversificação decorre de um mesmo dispositivo, que relaciona apenas dois tipos de unidades. Ou seja, trata-se, de fato, de um sistema altamente regular (e produtivo) de organização intratópica.

Nosso projeto de investigação e descrição da sistematicidade da organização intratópica encontra-se ainda em desenvolvimento. Assim, entendemos que os resultados aqui expostos devem ser tomados em caráter não definitivo. A continuidade de estudos sobre o tema pode mostrar a necessidade de ajustes ou revisões nas interpretações aqui propostas. Nesse sentido, uma perspectiva (crucial) de trabalho futuro envolve comparar as regras identificadas em diferentes materiais, de modo a se avaliar quais traços das regras seriam específicos dos materiais em que elas foram identificadas e quais traços poderiam ser comuns a regras de diferentes materiais e, portanto, característicos do fenômeno da organização intratópica em si.

Esse tipo de análise comparativa (complementada por uma ampliação do corpus aqui utilizado) pode viabilizar o alcance de uma maior particularização da regra que descrevemos para os editoriais novecentistas, por meio, por exemplo, do estabelecimento de uma maior predizibilidade das combinações permitidas entre unidades de posição e suporte. Ao mesmo tempo, a comparação entre regras pode revelar a generalidade de certos traços aqui descritos e sua relevância para a construção de SegTs mínimos em geral. A esse respeito, uma hipótese que nos parece profícua é a de que as unidades de posição e suporte, por serem postuladas, em grande medida, com base em uma das propriedades fundamentais da organização tópica -a distinção entre graus de abrangência temática - e se forem tratadas em termos um pouco mais genéricos do que aqui pensadas, podem, na verdade, vir a ser identificadas como unidades intratópicas dos mais diversos gêneros textuais, até mesmo como unidades intrínsecas ao processo de organização intratópica.

$\mathrm{Na}$ continuidade de trabalhos como este artigo, impõe-se também, dentre outros avanços, a discussão da correlação entre as regras intratópicas descritas e outras propriedades dos gêneros textuais considerados. No caso dos editoriais, a discussão certamente passa pela 
relação entre a natureza essencialmente argumentativa do gênero e a manifestação de posição e suporte como tese e argumento respectivamente, na provável maioria dos casos. A associação entre a organização intratópica e o funcionamento dos gêneros já toca também na questão do estudo histórico dos processos textuais e do português, o segundo projeto para o qual este artigo procura contribuir.

A esse respeito, com base nas pesquisas de Gomes (2007), Silva (2011) e Zavan (2009), que tratam, dentre outras questões, da história de editoriais, é possível notar que a impressa brasileira, num período que inclui o transcorrer do século XX, teria passado pelo que se poderia considerar como uma certa profissionalização, mudando de uma postura mais intersubjetiva, para um estilo mais objetivo. É plausível especular que uma mudança desse tipo estaria associada à ocorrência natural, no início do século $\mathrm{XX}$, de um editorial acerca de uma invasão de pernilongos na cidade, e à baixa probabilidade (talvez estranheza), a nosso ver, da veiculação de um editorial sobre esse assunto atualmente.

É esse tipo de observação histórica sobre os editoriais que deve ser correlacionada a alterações e manutenções na história da organização intratópica, como as brevemente apontadas neste artigo, que envolveriam um possível aumento de complexidade intratópica, em termos do número de domínios dentro do SegT mínimo, ao mesmo tempo em que envolveriam certa manutenção do grau de complexidade, em termos dos tipos de combinação entre posição e suporte. O cotejo dos resultados aqui oferecidos com análises da organização intratópica de editoriais de outras sincronias, anteriores e posteriores à primeira metade do século XX, deve possibilitar o levantamento de hipóteses e a depreensão de conclusões a respeito da diacronia desse processo de construção textual e, enfim, da história do português.

\section{REFERÊNCIAS}

ALMEIDA, M. M. S. Projeto de História do Português Paulista. Relatório Final de Pesquisa apresentado à FAPESP. São Paulo, 2017.

BAKHTIN, M. Estética da criação verbal. Tradução de Maria Ermantina Galvão Gomes Pereira. São Paulo: Martins Fontes, 1992.

BROWN, G.; YULE, G. Discourse Analysis. Cambridge: Cambridge University Press, 1983.

CASTILHO, A. T. (Org.). Para a história do português brasileiro. v. I. Primeiras idéias. São Paulo: Humanitas/FAPESP, 1998.

GARCIA, A. G. Estudo do processo de organização tópica em editoriais de jornais paulistas do século XXI. 277f. Dissertação (Mestrado em Estudos Linguísticos). UNESP, São José do Rio Preto, 2018.

GONÇALVES, S. C. L. O português falado na região de São José do Rio Preto: constituição de um banco de dados anotado para o seu estudo. Relatório científico final apresentado à FAPESP. São José do Rio Preto: UNESP, 2005. 
GOMES, V. S. Traços de mudanças e permanência em editoriais de jornais pernambucanos: da forma ao sentido. 313f. Tese (Doutorado em Linguística). UFPE, Recife, 2007.

HALLIDAY, M. A. K. As bases funcionais da linguagem. In: DASCAL, M. (Org.). Fundamentos metodológicos da lingüística. v.1. São Paulo: Global, 1978, p.125-161.

HANISCH, C. V. O processo de organização tópica em artigos de opinião de alunos da Universidade Federal do Acre-Câmpus Floresta. 467f. Tese (Doutorado em Estudos Linguísticos). UNESP, São José do Rio Preto, 2019.

HILGERT, J. G. Parafraseamento. In: JUBRAN, C. C; KOCH, I. G. V. (Orgs.). Gramática do português culto falado no Brasil. Campinas: Editora da UNICAMP, 2006, p. 275-299.

ILARI, R. Perspectiva funcional da frase portuguesa. 2. ed. rev. Campinas: Editora da UNICAMP, 1992.

JUBRAN, C. C. A. S. A Perspectiva Textual-Interativa. In: JUBRAN, C. C. A. S; KOCH, I. G. V. (Orgs.). Gramática do português culto falado no Brasil. Campinas: Editora da UNICAMP, 2006a, p. 27-36.

JUBRAN, C. C. A. S. Tópico Discursivo. In: JUBRAN, C. C. A. S; KOCH, I. G. V. (Orgs.). Gramática do português culto falado no Brasil. Campinas: Editora da UNICAMP, 2006b, p. 89-132.

JUBRAN, C. C. A. S. Uma gramática textual de orientação interacional. In: CASTILHO, A. T.; MORAIS, M. A. T.; LOPES, R. E. V.; CYRINO, S. M. (Orgs.). Descrição, história e aquisiçãa do português brasileiro. Campinas; São Paulo: Pontes; FAPESP, 2007, p. 313-327.

JUBRAN, C. C. A. S. Diacronia dos processos constitutivos do texto. In: HORA, D.; SILVA, C. R. (Orgs.). Para a História do Português Brasileiro: abordagens e perspectivas. João Pessoa: Ideia/ Editora Universitária, 2010, p. 204-239.

JUBRAN, C. C. A. S.; KOCH, I. G. V. (Orgs.). Gramática do português culto falado no Brasil - v. I: Construção do texto falado. Campinas: Editora da UNICAMP, 2006.

KOCH, I. G. V. Introdução à Linguística Textual. São Paulo: Martins Fontes: 2004.

KOCH, I. G. V. Desvendando os segredos do texto. 2. ed. São Paulo: Cortez, 2003.

MANN, W. C.; THOMPSON, S. A. Rhetorical Structure Theory: Toward a Functional Theory of Text Organization. Text, v. 8, n. 3, p. 243-281, 1988.

MARCUSCHI, L. A. Produção textual, análise de gêneros e compreensão. São Paulo: Parábola Editorial, 2008.

OLIVEIRA, G. A. Estudo do processo de estruturação interna de segmentos tópicos mínimos em cartas de leitores de jornais paulistas do século XXI. 194f. Dissertação (Mestrado em Estudos Linguísticos). UNESP, São José do Rio Preto, 2016.

PENHAVEL, E. Marcadores Discursivos e Articulação Tópica. 168f. Tese (Doutorado em Linguística). UNICAMP, Campinas, 2010. 
PENHAVEL, E. Processos de construção textual: uma abordagem diacrônica. In: ALMEIDA, M. M. S. Projeto de História do Português Paulista. Relatório Final de Pesquisa apresentado à FAPESP. São Paulo, 2017.

PINHEIRO, C. L. Estratégias textuais-interativas: a organização tópica. Maceió: Edufal, 2005.

SCHIFFRIN, D. Discourse markers. Cambridge: Cambridge University Press, 1987.

SILVA, S. S. O percurso sócio-histórico de uma tradição discursiva: da carta ao editorial. 274f. Tese (Doutorado em Linguística). UFRJ, Rio de Janeiro, 2011.

SOUZA, A. D. Estudo da organização intratópica e das relações retóricas em minissagas. 323f. Tese (Doutorado em Estudos Linguísticos). UNESP, São José do Rio Preto, 2020.

VALLI, M. V. O processo de organização tópica em dissertações escolares: da análise à emergência de uma abordagem para o ensino do gênero. 333f. Dissertação (Mestrado em Estudos Linguísticos). UNESP, São José do Rio Preto, 2017.

VAN DIJK, T. A. Text and contex: explorations in the semantics and pragmatics of discourse. 2. ed. Londres: Longman, 1982.

ZAVAM, A. S. Por uma abordagem diacrônica dos gêneros do discurso à luz da concepção de tradição discursiva: um estudo com editoriais de jornal. 420 f. Tese (Doutorado em Linguística). UFC, Fortaleza, 2009.

Recebido para publicação em: 9 out. 2020. Aceito para publicação em: 15 jan. 2021. 